\title{
Synthesis of porous LSM films on dense YSZ substrates for use in SOFC
}

\author{
D.P. Tarragó ${ }^{1}$, C.F. Malfatti ${ }^{1}$ and V.C. Sousa ${ }^{1}$ \\ ${ }^{1}$ School of Engineering \\ Federal University of Rio Grande do Sul \\ Porto Alegre - Rio Grande do Sul, CEP: 91509-900 (Brazil) \\ Phone:+5551 3308 9485, e-mail: diego.tarrago@ufrgs.br, celia.malfatti@ufrgs.br, vania.sousa@ufrgs.br
}

\begin{abstract}
.
Ceramic thin films are of great importance in the development and fabrication of devices such as SOFC. The porous microstructure of the electrodes is crucial for the overall performance of the SOFC and it is quite influenced by the fabrication process. In this sense, LSM films were obtained over $0,25 \mu \mathrm{m}$ rough $\mathrm{YSZ}$ dense substrates heated at $650^{\circ} \mathrm{C}$, using a salts solution and an airbrush. By XRD patterns the LSM perovskite phase was identified in both samples. The obtained films showed very high porosity with great pore size distribution. The LSM films exhibit grains with size around $60 \mathrm{~nm}$ in average. A more continuous film, practically without cracks, was obtained depositing $2 \mathrm{~mL}$ of the solution. The presence of microstructural defects in the film obtained wjth $1,5 \mathrm{~mL}$ of solution increased the cathode polarization compared with the one obtained with 2,0 $\mathrm{mL}$ of solution.
\end{abstract}

\section{Key words}

Thin films, strontium doped lanthanum manganite, solid oxide fuel cell.

\section{Introduction}

The development of inexpensive methods to obtain porous and thin ceramic films can reduce the cost of several technological products, including energy generation devices such as solid oxide fuel cells (SOFC). Strontium doped lanthanum manganite (LSM) is the most commonly used material as cathode of the SOFC and for this application the LSM must deposited over an electrolyte or an interconnector as a thin and porous film $[1,2]$.

In order to enhance the SOFC cathode performance the final microstructure must favour the gas flow through an interconnected porosity net and also possess high specific surface area to increase the amount of reactive sites, improving the catalysis of $\mathrm{O}_{2}$ reduction, which is a limiting factor in the overall reaction of the SOFC $[3,4]$. In this sense, by promoting an adequate gas flow through a high surface net of pores the performance of the SOFC device can be increased. Besides, a better catalytic activity is expected for nanostructured catalysts $[5,6]$.
In this study we intended to obtain nanostructured porous and thin LSM films over heated yttria stabilized zirconia (YSZ) dense substrates using a metal salts solution and an airbrush.

\section{Experimental}

\subsection{YSZ substrates}

The preparation of the YSZ substrates were carried out by mixing the YSZ powder (Sigma-Aldrich, 99.9\%) with 2,5 wt. $\%$ of an aqueous solution containing polyvinyl alcohol (PVA) binder at $10 \mathrm{wt} \%$, for $1 \mathrm{~h}$ in a ball mill. After drying at $120^{\circ} \mathrm{C}$, the powder was uniaxially pressed at $220 \mathrm{MPa}$ in a $12 \mathrm{~mm}$ diameter mould and sintered at $1450^{\circ} \mathrm{C}$ for $1.5 \mathrm{~h}$. A complete route fot the preparation of substrates is shown in Fig.1.

The apparent porosity of the sintered substrates was determined by the Archimedes method and a CETR PRO500 3D profilometer was used to analyse the surface profile and roughness $(\mathrm{Ra})$. Also, the YSZ substrates were observed in a Jeol JSM-6060 scanning electron microscope (SEM) and an X-ray diffraction (XRD) pattern was generated in a Philips equipment.

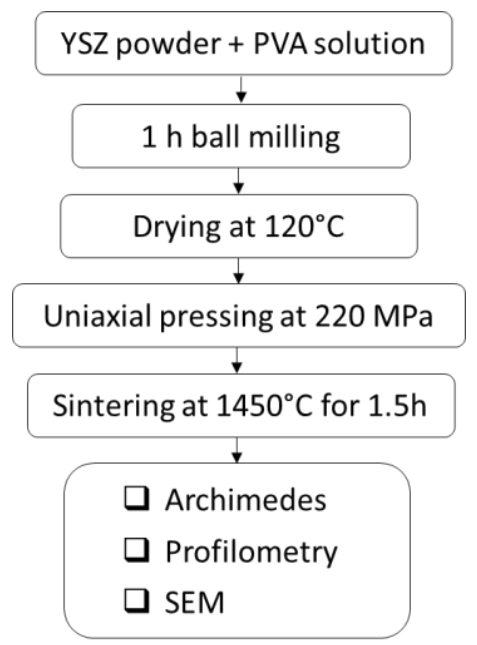

Fig. 1: Preparation route of the YSZ substrates. 


\subsection{LSM films}

For the deposition of the films $\mathrm{La}\left(\mathrm{NO}_{3}\right)_{3} \cdot 6 \mathrm{H}_{2} \mathrm{O}$ (lanthanum nitrate, 99\%), $\mathrm{Sr}\left(\mathrm{NO}_{3}\right)_{2}$ (strontium nitrate, 99\%) and $\mathrm{Mn}\left(\mathrm{NO}_{3}\right)_{3} \cdot 4 \mathrm{H}_{2} \mathrm{O}$ (manganese nitrate, $99 \%$ ), all from Vetec-Brazil, were added to an aqueous solution and dissolved. The calculation of salts' amounts aimed the obtaining of $\mathrm{La}_{0.9} \mathrm{Sr}_{0.1} \mathrm{MnO}_{3}$. The solution was airbrushed in YSZ substrates heated at $650^{\circ} \mathrm{C}$ in volumes of 1.5 and $2.0 \mathrm{ml}$. After the deposition, the films were calcined at $850^{\circ} \mathrm{C}$ for $1 \mathrm{~h}$.

The phase formed in the obtained films was determined by XRD and their microstructures were observed in SEM micrographs. Finally, electrochemical impedance spectroscopy (EIS) measurements were done in air from 500 to $850^{\circ} \mathrm{C}$ and recorded with an Autolab FRA in a frequency range of 0.1 to $10^{6} \mathrm{~Hz}$ and an $\mathrm{AC}$ signal of 50 $\mathrm{mV}$. The spectra were acquired during the samples' heating with a rate of $5^{\circ} \mathrm{C} / \mathrm{min}$ and 15 minute stabilization. A flowchart of the fabrication of the thin films is in Fig. 2, including the nomenclature of the samples, according to the amount of solution used to fabricate the film.

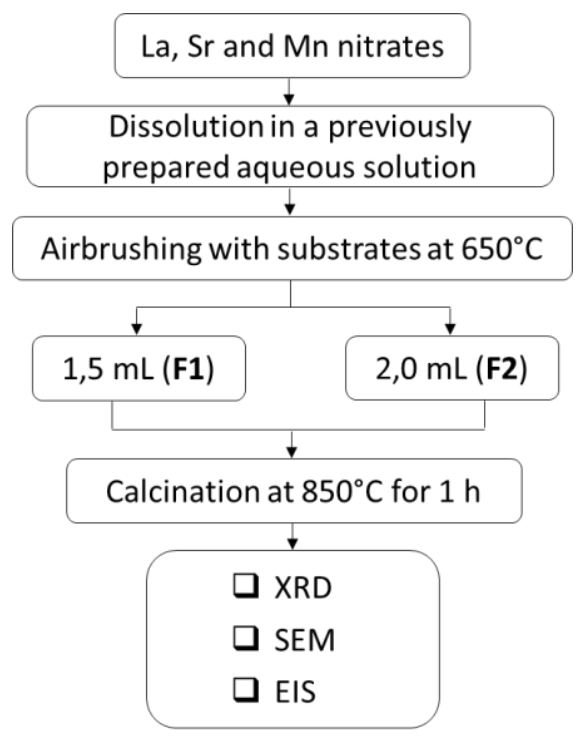

Fig. 2: Experimental flowchart.

\section{Results and Discussion}

\subsection{Characterization of YSZ substrates}

The YSZ substrates reached a densification of $97.6 \%( \pm$ $1.6 \%$ ). The 3D surface profile generated with the profilometer is shown in Fig 3. The substrates were as rough as $0,25 \mu \mathrm{m}$. For the deposition of thin films a surface with certain roughness helps on the mechanical anchoring of the coating, improving the film-to-substrate adhesion strength.

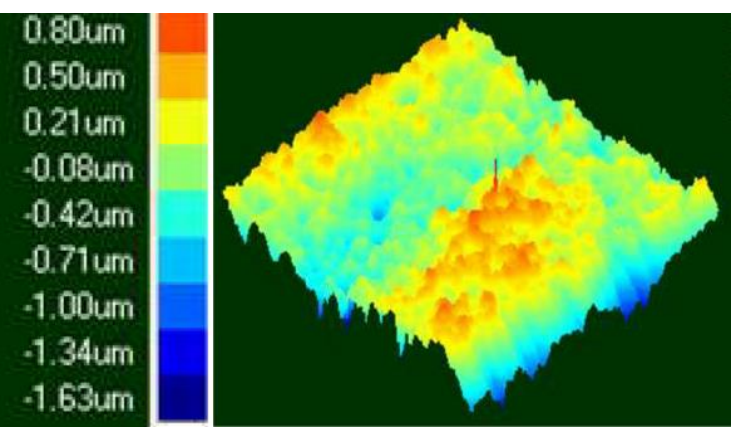

Fig. 3: YSZ substrate surface by 3D profilometry.

The microstructure of the substrate is shown in the SEM micrograph of Fig. 4. A submicrometric grain size is observed with a small presence of pores, corresponding to its high densification.

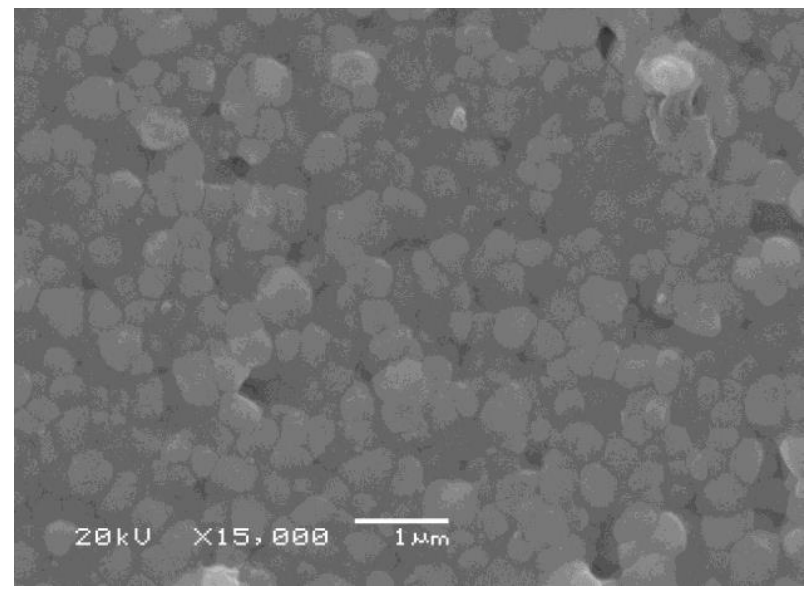

Fig. 4: SEM micrograph of the YSZ substrate surface.

\subsection{Characterization of LSM films}

Over the surface with the characteristics observed before the LSM films were deposited. The Fig. 5 shows a YSZ substrate before the deposition (left) and a YSZ substrate coated with the LSM film after calcination (right).



Fig. 5: Uncoated (left) and coated (right) substrate.

In Fig. 6 are shown the generated XRD patterns. It is possible to determine the formation of the LSM perovskite phase (ICDD $\mathrm{n}^{\circ}$ 00-051-0409) on both samples, as identified by the markers $(\bullet$ and $\Delta)$. 


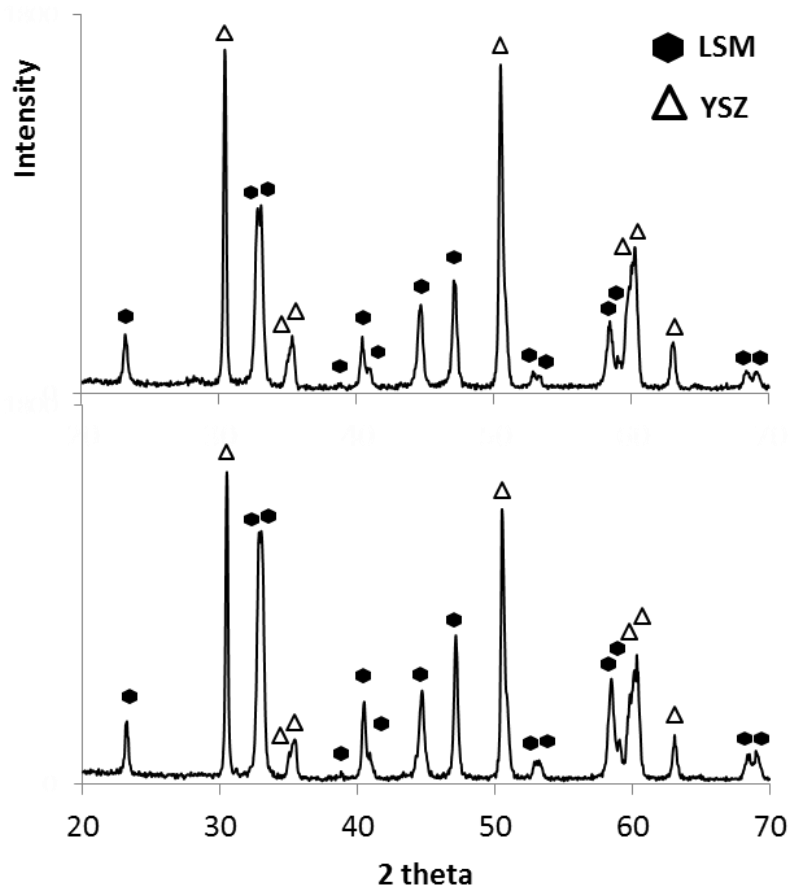

Fig. 6: XDR patterns of the deposited films.

Also, peaks of the YSZ substrate (ICDD n 00-048-0224) are observed, they can be appearing because of the films' porosity or due to the presence of cracks and discontinuities in the coatings. Nevertheless, the defined peaks of the LSM rhombohedral perovskite phase indicate a well crystalized phase.

In the lower magnification SEM micrographs on Fig. 7 it is possible to observe a porous microstructure. They allow us to infer about the continuity of the films and the presence of cracks, as seen in the film F1 (top). In F2 it seems that there are no cracks and also this film is more continuous, judging by the observation of its surface. The continuity of film F2 may explain the more relatively intense peaks in this sample's XRD pattern.

When observed in medium magnification (Fig. 8), the presence of pores is better distinguished. The larger ones have a diameter of approximately $2 \mu \mathrm{m}$ and the pore size distribution appears to be more effective in F2 (bottom). In this film it can also be observed that, besides these larger pores, the microstructure is formed by several other pores within a great range of size distribution.

In larger magnification, Fig. 9 very small pores are observed, especially in film F2. In this sample, it is possible to see that, in addition to the larger pores, there is a vast nanoscaled interconnected porosity net. At this level, F1 shows a denser microstructure, while F2 has a great amount of pores with very small sizes, below 100 $\mathrm{nm}$. As well, in both samples the grain size is around 100 $\mathrm{nm}$.
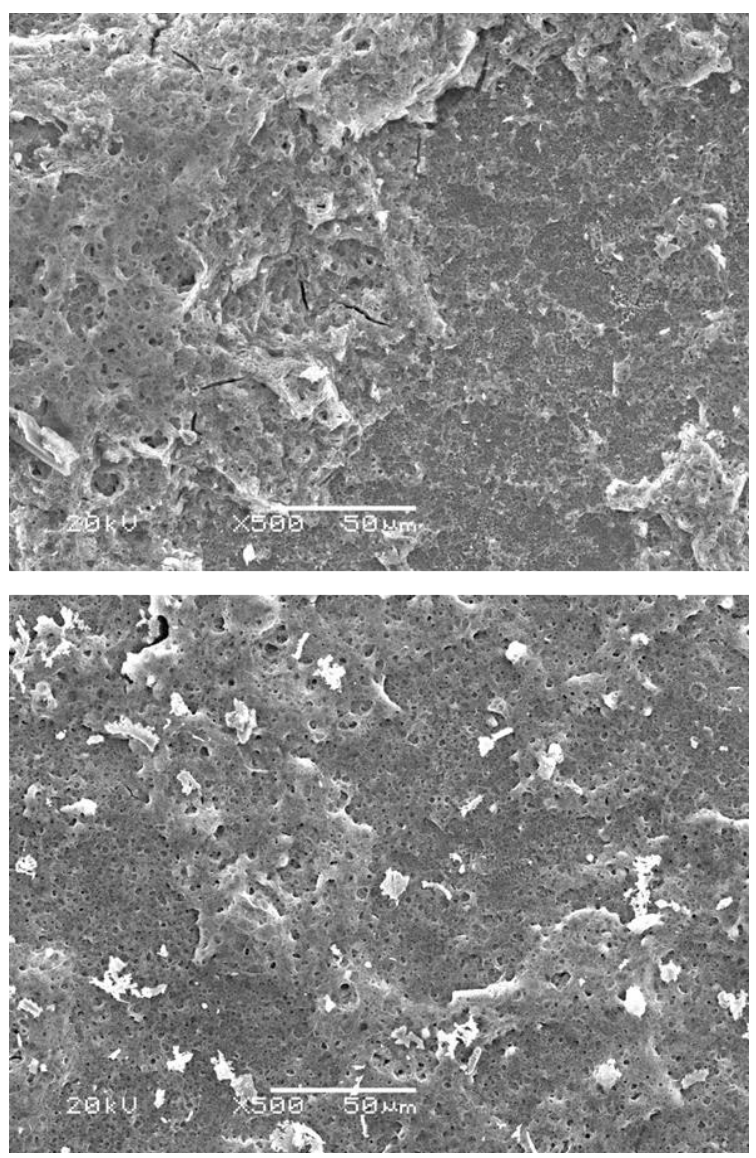

Fig. 7: SEM micrographs of F1 (top) and F2 (bottom) (at $0.5 \mathrm{k}$ ).
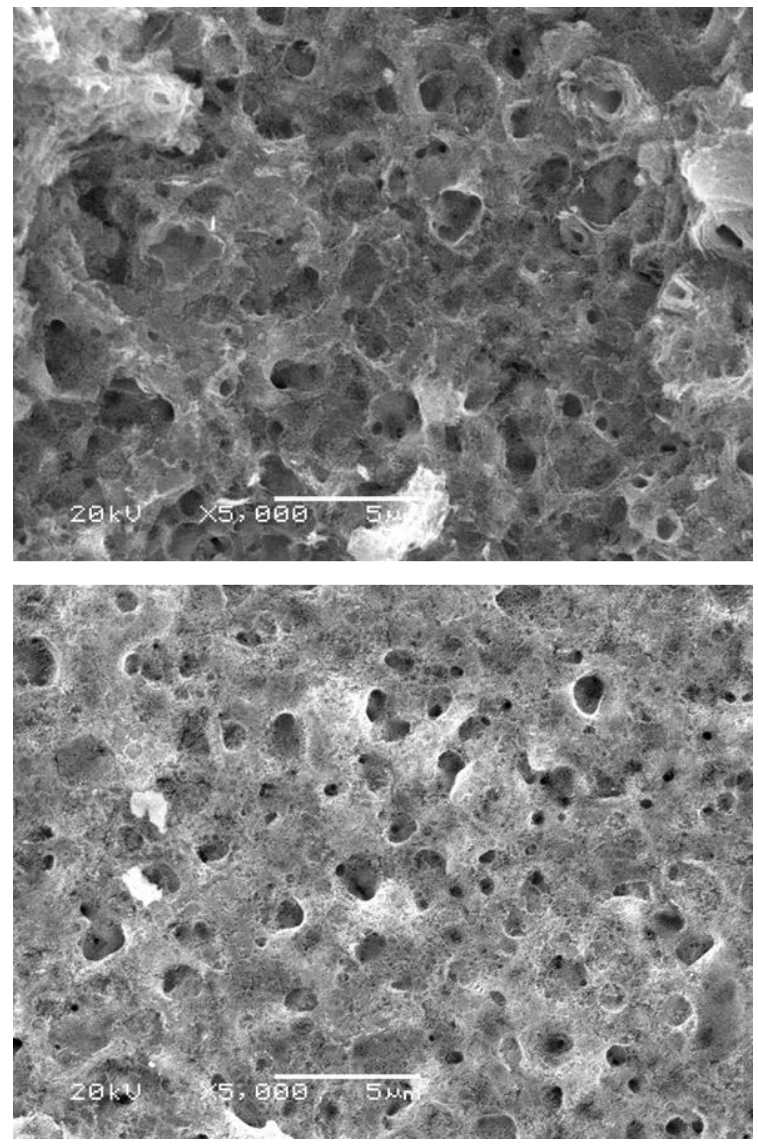

Fig. 8: SEM micrographs of F1 (top) and F2 (bottom) (at 5k). 



Fig. 9: SEM micrographs of F1 (top) and F2 (bottom) (at 5k).

The nanostructured catalyst films where analysed by EIS and in Fig. 10 the spectra of both samples at $750^{\circ} \mathrm{C}$ is shown. The resistance that appear in low frequencies was attributed to the lack of a contact electrode. We can assume that F2 is thicker than F1, because of higher amount of solution used in its fabrication. However, the high frequencies phenomena, attributed to the electrode polarization [8], shows that F2 has smaller polarization resistance.

The circuit associated to the obtained spectra is in Fig. 11, where $\mathrm{Rs}$ is the electrolyte resistance. The parallel resistances $R p_{1}$ and $R p_{2}$ together are the total polarization resistance and $\mathrm{Rp}_{3}$ is the electrode effect. The constant phase element (CPE) was used to help fitting the Nyquist plots.

The presence of cracks in F1 may explain its higher polarization, observed in the EIS curves. Microstructural defects can concur against films thickness to determine total polarization. In other words, a thicker film tend to present higher polarization, but greater amounts of microstructural defects also increase polarization. It is possible then, that F2, although thicker, has less microstructural defects, as observed in SEM micrographs.


Fig. 10: EIS spectra of LSM films deposited on YSZ.

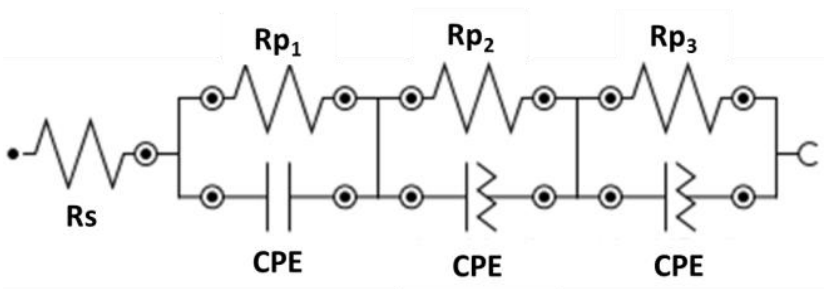

Fig. 11: Equivalent circuit associated to the EIS spectra.

\section{Conclusion}

It was possible to obtain LSM films with adequate microstructure over a YSZ substrate with $0.25 \mu \mathrm{m}$. The obtained films showed very high porosity with great pore size distribution. The LSM films exhibit grains with size around $60 \mathrm{~nm}$ in average. A more continuous film, practically without cracks, was obtained in F2. The presence of microstructural defects in F1 increased the cathode polarization compared with $\mathrm{F} 2$. 


\section{Acknowledgements}

The authors would like to thank the Conselho Nacional de Desenvolvimento Científico e Tecnológico (CNPq Brazil), for financial support, and the Laboratório de Materiais Cerâmicos (LACER) at our university, for lending some of the equipment for the characterization.

\section{References}

[1] EG\&G Technical Services, Science and Applications International Corporation, Fuel Cell Handbook, Department of Energy, USA (2002).

[2] G. Hoogers (Editor), Fuel Cell Handbook, CRC Press, USA (2003).

[3] D. Hotza, J.C. Diniz da Costa, "Fuel cell development and hydrogen production from renewable sources in Brazil", International Journal of Hydrogen Energy (2008), 33, 49154935.

[4] H. Gleiter, "Nanostructured materials: basic concepts and microstructure", Acta Materialia (2000), 48, 1-29.

[5] V.A.C. Haannappel, J. Mertens, D. Rutenbeck, C. Tropartz, W. Herzhof, D. Sebold, F.Tietz, "Optimisation of processing and microstructural parameters of LSM cathodes to improve the electrochemical performance of anode-supported SOFCs", J. Power Sources (2005), 141, 216-226.

[6] A.J. Darbandi, H. Hahn, "Nanoparticulate cathode thin films with high electro-chemical activity for low temperature SOFC applications", Solid State Ionics (2009), 180, 13791387.

[7] B. Moreno, R. Fernandez-Gonzáles, J.R. Jurado, A. Makradi, P. Nuñez, E. Chinarro, "Fabrication and characterization of ceria-based buffer layers for solid oxide fuel cells", International Journal of Hydrogen Energy (2014), 39, 54335439. 